\title{
HOW TO IMPROVE THE PERFORMANCE OF AGRICULTURE IN MONGOLIA BY ICT
}

\author{
${ }^{1}$ Yukitsugu Takahashi, ${ }^{2}$ Munkhtuya Dooliokhuu, ${ }^{3}$ Atsushi Ito, ${ }^{4}$ Kazuki Murata \\ ${ }^{1}$ Department of Agriculture Farm, Utsunomiya University, Moka-shi, 321-4415 \\ ${ }^{2}$ Department of Mathematics, Physics and Information Technology, School of Engineering and Technology, \\ Mongolian University of Life Sciences, Ulaanbaatar, Mongolia, 17024 \\ ${ }^{3}$ Department of Engineering, Utsunomiya University, Utsunomiya-shi, 321-8585 \\ ${ }^{4}$ Fujitsu Frontech, Inagi-shi, Tokyo, Japan, 206-8555 \\ ${ }^{2}$ it@muls.edu.mn
}

\begin{abstract}
Agriculture is one of the most important sectors for the Mongolian economy. Also, self-sufficient food is a significant target that has a vital role in the food safety of people in Mongolia. But due to climate change, not proper management, and lack of technology, the Mongolian agricultural sector is facing several issues. So this article aims to find some potential solutions to improve this situation, especially for the crop production sector in Mongolia. To define the current situation of Mongolian agriculture, we used statistical data and reports and recent scientific articles as well as online sources. The current situation of Mongolian agriculture is defined using SWOT analysis reported by the Ministry of Food, Agriculture, and Light Industry of Mongolia. Based on this research, we discuss the possibility of using a drone to improve the performance of agriculture in Mongolia. As a result, a drone is effective in enhancing the performance of agriculture performed by householders. Also, two effective models that are based on ICTs to address soil erosion and harvest losses issues in Mongolia are defined in this article.
\end{abstract}

Keywords: Agriculture technology, Drone, ICT, IoT, NDVI.

(JEL Classification: Q16)

\section{INTRODUCTION}

The purpose of this article is to find some possible solutions to improve Mongolian agriculture by Information Communication Technologies (ICTs). In Mongolia, the agricultural sector consists of two subsectors, namely, animal husbandry and crop production. This sector is contributing 10.8 percent of the Gross Domestic Product (GDP), and 55.8 percent of the total labor force is working in the sector. In 2018, approximately 511.8 thousand hectares cultivated area was used for crop production, with 7.1 percent of this presently under irrigation. This land, both irrigated and non-irrigated, is used by 1,422 farm companies and 15,862 householders to produce agricultural goods for domestic consumption (NSO, 2018).

The principal crops are wheat and potatoes, which are widely grown in all regions and cover more than half of the country's cultivated area. Cereals, fodder plants, oil crops, vegetables, and some fruits cover the rest of the area. Mongolia's 2030 Sustainable Development Vision set a goal to be self-sufficient in grain, potatoes, and vegetables by 203 . However, Mongolia depends on imports for more than 20 percent of their food goods. The primary imported goods are all type of rice, vegetables, fruits, leguminous plants, eggs, and food oil are imported from other countries, particularly China, $100 \%, 43.5 \%, 92.9 \%, 100 \%, 49.7 \%$, and $92.7 \%$, respectively (MOFALI, 2019). Hence, the Ministry of Food, Agriculture, and Light Industry of Mongolia aims to increase vegetable production for the domestic market. The target number of the harvest of vegetables is 198 thousand tons in 2020 (MOFALI, 2018) (Figure 1).

From this background, this article focus on finding some potential solutions based on ICTs to increase vegetable production in Mongolia. As the tendency of the World, The 
Figure 1. Information of vegetables production between 1990 and 2017, and purposed level by 2020

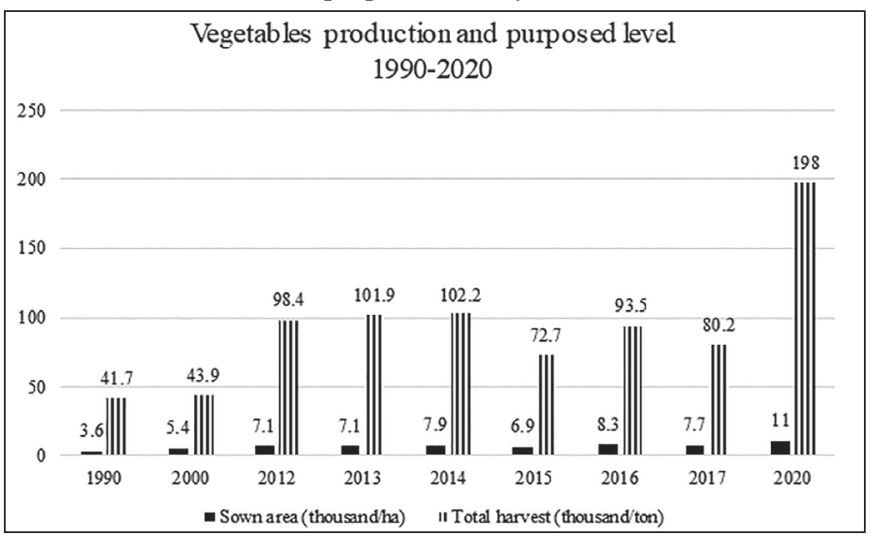

Source: http://mofa.gov.mn/exp/blog/8/71\# (MOFALI, 2018)

Table 1: SWOT analysis of crop production sector in Mongolia

\begin{tabular}{|c|c|c|}
\hline \multirow[b]{2}{*}{ 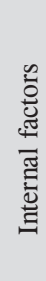 } & Strengths & Weaknesses \\
\hline & $\begin{array}{l}\text { Adapted seed sorting } \\
\text { Produced agrotech } \\
\text { Implemented mechanisms }\end{array}$ & $\begin{array}{l}\text { Technology is old and harm- } \\
\text { ful for resources } \\
\text { Financial ability of farmers } \\
\text { Unstable production } \\
\text { Weak market, quality of seed } \\
\text { supply }\end{array}$ \\
\hline \multirow[b]{2}{*}{ 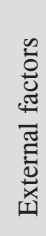 } & Opportunities & Threats \\
\hline & $\begin{array}{l}\text { Resource of arable land } \\
\text { Demand for market } \\
\text { Encourage of the Government } \\
\text { Interests of farmers }\end{array}$ & $\begin{array}{l}\text { Climate change } \\
\text { Input depends on import } \\
\text { Shortage of labor } \\
\text { Soil erosion } \\
\text { Limited export condition }\end{array}$ \\
\hline
\end{tabular}

Source: Master plan of Mongolian agriculture 2011-2021 (MOFLI, 2011)

Food and Agriculture Organization of the United Nations has reported ICTs in agriculture can potentially contribute to improving both the productivity and sustainability performance of the agriculture and food sector towards the realization of the Sustainable Development Goals. For example, the precision application of agrochemicals can reduce the amounts of pesticides and fertilizers. At the same time. increasing yields and reducing possible negative sideeffects on soil and water, better weather, and market data enables more effective farm production decisions, reducing waste and loss on the farm (FAO, 2017).

Section 2 mentions materials and methods. This section includes (1) existing problems in Mongolian agriculture, (2) related works to use ICTs to improve the productivity of agriculture, (3) the outline of the result of our research to estimate the growth stage of rice by using a drone. Based on the discussion in section three, we discuss the possibility of using a drone for vegetable farming and the possibility to develop automation systems based on IoT for agriculture in Mongolia in section 4. Finally, the conclusion is mentioned in section 5 .

\section{MATERIALS}

\section{Existing problems in Mongolian agriculture}

The Mongolian government has reported "Master plan of Mongolian agriculture 2011-2021" that define the current situation and display a plan of Mongolian agriculture (MOFALI, 2011). In this master plan, strengths, weaknesses, opportunities, and threats (SWOT) analysis of the crop production sector is presented in the table(Table 1). There are many positive factors, such as the huge arable land, interests of farmers, and lots of needs in the domestic market. From this analysis, two major issues that might be solved by ICTs discussed in this article.

These issues are soil erosion and harvest losses in the crop production sector. The soil erosion is a less-discussed form of Mongolia agriculture even soil is a crucial point of agriculture. The soil erosion is increasing continuously because of the intensive use of soil and less maintenance for soil, especially the agricultural area. The arable soils of Mongolia comprise dark chestnut and chestnut soils, which are typical of soils that evolved with steppe vegetation. These soils are inherently fertile but shallow soils, with an average depth of $30 \mathrm{~cm}$. Because of their light texture, moisture retention is low, and the soils are susceptible to erosion (B. Batkhuyag \& Kh.Batnaran, 2018). The foremost need for this issue is to develop a database of soil information about Mongolian farming regions for farmers. The information about soil ranging from the type of soil, what crops would be suitable, how long it can be used for farming to how to maintain this soil should be provided for farmers. Based on this background, this article also focuses on to develop a model using IoT for soil information databases for farming five regions in Mongolia.

Another issue is the harvest losses. It is often said that crop production in Mongolia mostly depends on the weather condition, also B.Batkhuyag \& Kh.Batnaran (2018) presented that in the extreme continental climate, with long cold winters and low precipitation, it is considered as one of the critical factors to agricultural production in Mongolia. The crop yield in any given area can fluctuate up to $50 \%$ due to weather conditions of given year and season, and it might even be lost altogether (Bolormaa, Lkhagvasuren, Gantuya, Gnakhuyag, \& Altanzul, 2018). So, to monitor the crop field and to increase the vegetable production, we need to implement ICTs for crop field. Also, lack of irrigation and less automation system might be another cause of this issue because irrigated fields occupy only 7.1 percent of the total cultivated area.

A large number of crops are wheat and potatoes, which are widely grown in all regions and covers more than half of the country's cultivated area. For example, the total cultivated area is 511.8 thousand ha, 71.7 percent for wheat, 14 percent for industrial crops, 9 percent for fodder plants, 25 percent for potatoes, 1.7 percent for vegetables, 0.8 percent for fruits and 0.2 percent for medical plants (NSO, 2019). It can be concluded that other (except wheat and potatoes) crops production efficiency in Mongolia is relatively low because the 
production depends mainly on rainfall and weather. Therefore, farmers do not have the technology to increase their crop productivity. In addition, decreasing the labor force can be impacted by this issue. In fact, nowadays, young people do not want to work in the farming field, and most youths leave for the city. Due to decreasing labor, many automation systems and robots are introduced in developed countries, especially Japan, and it can bring some benefits from automation for agriculture.

\section{Related works to use ICTs to improve the productivity of agriculture}

In this subsection, we discuss relevant prior research on two aspects. The first involves agricultural drones, while the second aspect focuses on sensors in agriculture.

\section{Drones in agriculture}

Last decade, drones were applied in many studies. The use of drones in agriculture is extending at a brisk pace in crop production, early warning systems, disaster risk reduction, forestry, fisheries, as well as in wildlife conservation (FAO and ITU, 2018). In this study, we focus on to improve productivity in a crop field. For example, crop production: using GPS and sensors for collecting relevant data in the field, a drone can do soil health scans, monitor crop health, assist in planning irrigation schedules, apply fertilizers, estimate yield data and provide valuable data for weather analysis (Marthinus, R., \& Tania, P., 2017). Also, many studies focused on the growth condition of crops using a drone in recent years. For instance, a study introduced a complete system that combines the UAV platform, a UAV-borne crop-growth sensor, and a ground-based data processor. The system can continuously and conveniently obtain the NDVI and RVI values of the crop canopy online (as well as growth indices including LNA, LAI, and LDW) with high throughput and is not limited by the terrain (Jun, et al., 2017). Also, Frank Veroustraete said that the ability of a drone is inspected in-progress crops from about 100 meters height using the Normalized Difference Vegetative Index (NDVI) or near-infrared (NIR) sensors (Veroustraete, 2015). It seems that agricultural drones will be continuously used in agriculture in the future.

Table 2. Detectable wavebands of Sequoia.

\begin{tabular}{ccc}
\hline Waveband & Wavelength(nm) & Band width(nm) \\
\hline Green (G) & 550 & 40 \\
Red (R) & 660 & 40 \\
Red Edge (RE) & 735 & 10 \\
Near InfraRed (NIR) & 790 & 40 \\
\hline
\end{tabular}

\section{Sensors in agriculture}

Jhonattan et al. (2019) presented a case study of sensing, smart and suitable technologies applied for the agri-food sector: an intelligent greenhouse, a sun tracker trajectory, a hexapod robot for field monitoring and an agricultural drone. And Jirapond et al. (2019) introduced a system optimally watering crops based on wireless sensor networks. So they illustrated this optimal watering system can reduce costs and improve the productivity of farming. In general, sensors can detect events, acquire data, measure changes that occur in a physical environment, and collect information that is processed by a control system. Some of the most common applications of sensing technologies are in monitoring systems, control systems, autonomy, and optimization. Also, due to the importance of sensing technologies, there are efforts to improve sensing systems to increase their processing capability and reduce the size, energy consumption, and costs. Moreover, there is research that Brazilian researchers Dieisson, et al. (2018) surveyed to define leader countries in the smart farming research filed.

As a result of this study, China, the United States, South Korea, Germany, and Japan have contributed the most significant number of scientific studies to this field. Leadership in publishing SF research is associated with how much countries spend on R\&D annually. Countries that invest more in R\&D have the highest number of publications and become leaders in smart agriculture technologies in the future.

\section{RESEARCH METHODOLOGY}

We performed research to evaluate the effectiveness of estimating the growth condition of rice by a drone (Murata, Ito, Takahashi, Hatano, 2018). We used NDVI (Normalized Difference Vegetation Index) images and realized higher accuracy classification of the growth stage of rice. To take NDVI images, we used a drone (Phantom 3) and Sequoia (Parrot SEQUOIA). Table 2 shows detectable wavebands of Sequoia. Sequoia. It can get four wavebands, Green, Red, Red Edge, and Near-Infrared. Equation (1) shows NDVI.

In this study, paddy's growth stages are categorized in six, such as (a) Transplanting stage, (b) Tillering stage, (c) Panicle forming stage, (d) Booting stage, (e) Heading stage, (f) Ripening stage. We used Deep Learning to detect the growth stage using a drone and multi-spectrum camera.

Figure 2. Mesh division

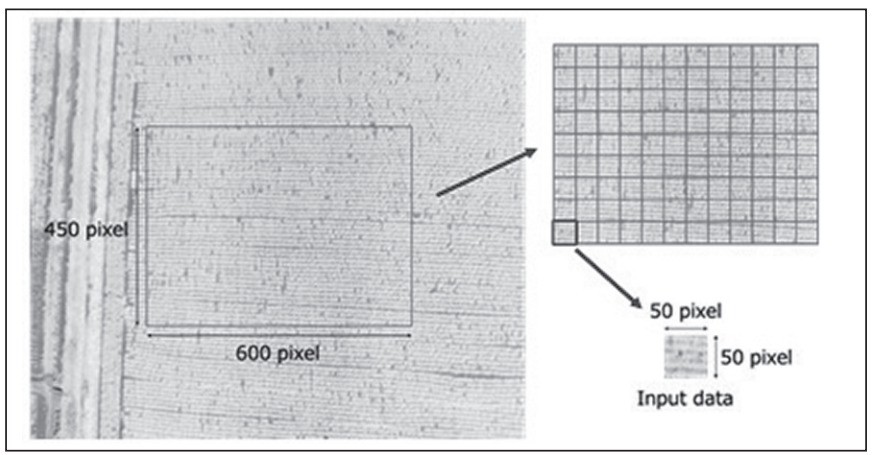


We divided the NDVI images into a rectangular mesh and used them as input to Deep Learning. We used the center of the NDVI images so that NN (Neural Network) doesn't learn features of footpath between rice fields. The size is 600 pixels $\times 450$ pixels. To increase training data, we cut the images to 50 pixels $\times 50$ pixels (Figure 2). It seems that this cutting has an advantage of detailed growth stage classification. We randomly selected 30 pairs (Red and Near Infrared) of captured images par a day and created NDVI images. Processing above, the number of images is $12 \times 9 \times 30=3240$. We took care of making sure there was no footpath in the center of images.

We implemented some experiments using Deep Learning in Python using Keras, a deep,learning library. We used CNN (Convolutional Neural Network) as a Deep Learning model, cross-entropy function as error function, Adadelta as Optimizer, accuracy as metrics, hold-out as validation methods. Training data is $80 \%$ of all data, and test data is 20 $\%$. We also used early stopping, monitoring loss of training data. It reduces the effect of over-fitting. Table 3 shows other parameters of Deep Learning. All of the above settings are common in the following three experiments. It shows a detail of CNN. The first two Dropout rates are 0.25, and the last one is 0.5. Most of the Activation function is ReLU (Rectified Linear Unit), and the last one is the Softmax function.

Table 3. Parameters of Deep Learning.

\begin{tabular}{cc}
\hline Parameter & The number of parameters \\
\hline Training data & 64800 \\
Test data & 16200 \\
Mini-batch size & 32 \\
Epoch & 50 \\
Class & 5 \\
\hline
\end{tabular}

Table 4. Shooting height and image resolution of Sequoia.

\begin{tabular}{cc}
\hline Shooting height $(\mathrm{m})$ & Image resolution $(\mathrm{cm} /$ pixel $)$ \\
\hline 30 & 3.7 \\
60 & 7.4 \\
100 & 12.4 \\
\hline
\end{tabular}

As mentioned in, we classified the growth stages of paddy rice by $\mathrm{CNN}$ using images taken at $60 \mathrm{~m}$ and $100 \mathrm{~m}$ high. In this paper, we refer to images by scaling the images captured at $30 \mathrm{~m}$ high to images with a resolution of $60 \mathrm{~m}$ and $100 \mathrm{~m}$ as Artificial height images. Table 4 shows the image resolutions of these heights. We also refer to Images captured at $60 \mathrm{~m}$ and $100 \mathrm{~m}$ high as Natural height images. We conducted two experiments of classification using Artificial height images and Natural height images. To confirm the classification accuracy of the growth stage using the data of 2018, we conducted a pre-experiment using images taken at $30 \mathrm{~m}$ high.
Table 5 shows the classification accuracy of the train data and test data of each height. The results indicate that the classification accuracy is almost the same as the previous experiment. Table 6 shows classification accuracy when inputting each Artificial height image into the model after learning. The results indicate that accuracy is much higher than when inputting natural height images (Table 6)

As a result, (1) there is no difference between two heights (60 meters and 100 meters), (2) the learned model from Natural height can accept the Artificial height images.

Table 5. Classification accuracy.

\begin{tabular}{ccc}
\hline Height $(\mathrm{m})$ & $\begin{array}{c}\text { Accuracy of train data } \\
(\%)\end{array}$ & $\begin{array}{c}\text { Accuracy of test data } \\
(\%)\end{array}$ \\
\hline 60 & 86.1 & 86.5 \\
100 & 86.5 & 87.8 \\
\hline
\end{tabular}

Table 6. Classification accuracy inputting Artificial height images.

$\begin{array}{cc}\text { Height }(\mathrm{m}) & \text { Accuracy }(\%) \\ 60 & 99.6\end{array}$

\section{RESULTS AND DISCUSSION}

Possibility to use a drone in Mongolia for vegetable farming

National Statistics Office, (2018) companies cultivated vegetables in 2.1 thousand ha while householders cultivated in 6.7 thousand ha. Average vegetable farming size between 500 ha and 1000 ha for a company, and it is approximately 0.2 ha for a householder. According to the result, to estimate the growth stage of rice using drones from different height, the accuracy does not be affected by the height under $100 \mathrm{~m}$. As our experience, a drone with a fully charged battery can fly 20 minutes and can cover 1.5 ha at the height is $30 \mathrm{~m}$. If the height is $100 \mathrm{~m}$, the cover area can be ten times wide, 15 ha. Using these parameters, we can estimate the required flight of the drone, as described in Table 7. If we use $30 \mathrm{~m}$, only the size of the vegetable field of the householder is realistic. However, if we use $100 \mathrm{~m}$, the vegetable field of the householder is also the target of growth stage estimation by drone. The field owned by a company. The current drone technology cannot be applicable. If the drone technology, especially battery technology, is progressed, the wider area is the target of precise farming using drones.

From an economic perspective, using drones can be cheaper than other technologies as satellites. The cost of pictures taken by satellites is expensive. The average price of a picture is about $\$ 500$, and If we need 10 pictures to see the trend of NDVI, it costs about $\$ 5,000$. Analysis cost of pictures to calculate NDVI and estimate the content amount of protein are additional. In some cases, such additional cost requires $\$ 80$ thousand to $\$ 100$ thousand (Murata, Ito, Takahashi, Hatano, 2018).

For drones, the average price of a drone is $\$ 2,000$ for 
taking pictures in the normal zone, the price of a drone for professional is around $\$ 5,000$, and an agricultural drone price starts around $\$ 30$ thousand.

Table 7. Calculation of the required the number of drone (or flights)

\begin{tabular}{cccc}
\hline & $\begin{array}{c}\text { Example of } \\
\text { dimension of the } \\
\text { farm land }\end{array}$ & $\begin{array}{c}\text { The number of } \\
\text { drones to cover } \\
\text { the area }(30 \mathrm{~m})\end{array}$ & $\begin{array}{c}\text { The number of } \\
\text { drones to cover } \\
\text { the area }(100 \mathrm{~m})\end{array}$ \\
\hline $\begin{array}{c}\text { 1h ha } \\
\text { 33.3 ha }\end{array}$ & $50 \mathrm{~m} \times 50 \mathrm{~m}$ & 1 & 1 \\
500 ha & $2,000 \mathrm{~m} \times 2,500 \mathrm{~m}$ & 333 & 2 \\
1,000 ha & $3,300 \mathrm{~m} \times 3,300 \mathrm{~m}$ & 667 & 33 \\
2,000 ha & $5,000 \mathrm{~m} \times 4,000 \mathrm{~m}$ & 1,333 & 67 \\
\hline
\end{tabular}

Possibility to use a drone in Mongolia for vegetable farming

This article offers two potential solutions based on the Internet of things for vegetable production.

The first solution is to develop a soil information database to protect and recover soil erosion in farming regions. It should be developed the following steps (Figure 3):

1. Gathering information about soil from the farming regions

2. Develop sensor networks

3. Taking information (images, sensor data) by drone

4. Analyze data by AI (CNN, RNN, Reinforce Learning)

5. Develop a map of soil distribution

6. Construct a QA system using AI

The QA system is essential for farmers in different situations, so that it should be designed for the universal uses for farmers.

The second solution is to design and develop a fully automatic system for crop field. It should improve not only productivity in the crop field but also reducing costs and labor. To develop this system, we should follow these steps (Figure 4):

1. We can design and develop a node system by sensor networks in the crop field to gather data such as temperature, humidity, and soil moisture. Also, a drone in which a multispectral camera can take NDVI photos.

2. We design and develop a monitor system, and it can help estimate field variables ranging from growth stage, soil status, atmospheric conditions to a biomass of plants. Also, it would be interactions with the user, which should be interfaced with smartphone and web application.

3. We can design and develop a growth model that is demanded data storage from collected data (Han and Kamber 2006). Then we can analyze the information to splay pesticide and insecticide automatically and calculate the amount of pesticide to maximize taste and crop yield.
Figure 3. Overview of soil information database

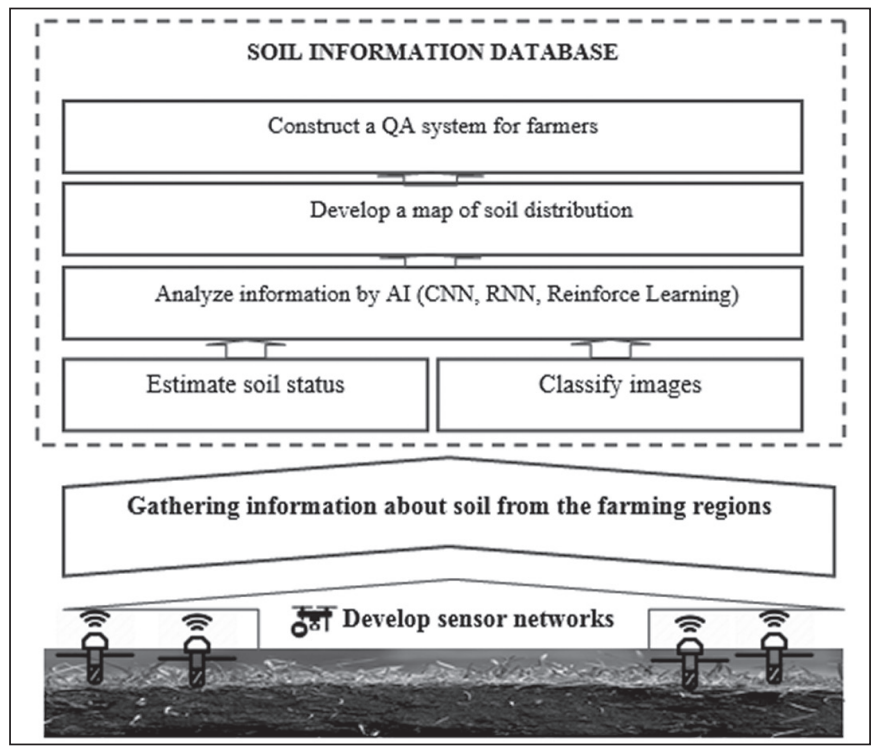

Figure 4. Overview of the fully automatic robot for crop yield

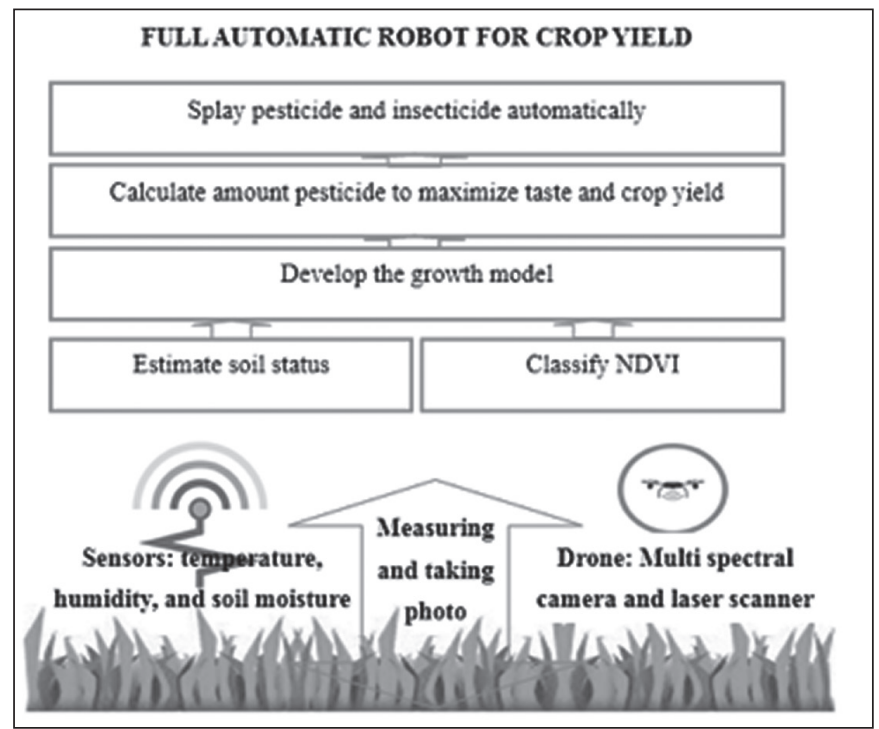

\section{CONCLUSIONS}

ICTs are applied in agriculture to improve crop production and quality in many developed countries. Also, it can reduce the cost of crop production. In this article, we aimed to present some possible solutions based on ICTs for Mongolian agriculture. So, we defined the current situation of Mongolian crop production using some reports and statistics data. Also, we mentioned that drone and sensor technologies bring many benefits from reducing costs and controlling real-time data in many agricultural countries.

We analyzed the possibility of using a drone to improve the performance of agriculture in Mongolia based on the result of our previous research to estimate the growth stage of rice by drone with a multi-spectrum camera. Thus, a drone is effective in improving the performance of agriculture performed by 
householders. Besides, two models of the automatic system based on ICTs are offered for soil erosion and harvest loss issues in this article. Finally, we suppose that these systems can bring many benefits from reducing costs and sharing real-time information for Mongolian crop production.

\section{REFERENCES}

B.Batkhuyag, \& Kh.Batnaran. (2018). Potential impacts of climate change on Mongolia's plant protection status quo. Mongolian Journal of Agricultural Sciences Vol 24 No 02 (2018) https://doi.org/10.5564/ mjas.v24i02.1111, 26-32.

Bolormaa, D., Lkhagvasuren, D., Gantuya, J., Ganhuyag, L., \& Altanzul, R. (2018). Results of pasture monitoring research. Mongolian Journal of Agricultural Sciences, 22(3) (2018), 41-45.

Dieisson, P., Paulo, D. W., Edson, T., Caroline, P. S., Vitor, F. D., \& Giana, d. V. (2018). Scientific development of smart farming technologies and their application in Brazil. Information processing in agriculture $5,21-32$.

FAO. (2017). Information and Communication Technology. Rome: Food and Agriculture Organization of the United Nations.

FAO and ITU. (2018). E-agriculture in action: drones for agriculture. Bangkok, Thailand.

Han, J. K. (2006). Data Mining Concepts and Techniques. Morgan Kaufmann publisher.

Jhonattan, M., Pedro, P., Arturo, M., \& Paul, W. (2019). Sensing Smart and sustainable technologies for Agri-Food 4.0. Computers in Industry 108, 21-36.

Jirapond, M., Nathaphon, B., Siriwan, K., Narongsak, L., Apirat, W., \& Pichetwut, N. (2019). IoT and agriculture data analysis for smart farm. Computers and Electronics in Agriculture 156, 467-474.

Jun, N., Lili, Y., Jingchao, Z., Weixing, C., Yan, Z., \& Xiuxiang, T. (2017). Development of an Unmanned Aerial Vehicle-Borne Crop-Growth Monitoring System. Sensors doi: 10.3390/s17030502.

Marthinus, R., \& Tania, P. (2017). The influence of drone monitoring on crop health and harvest size. 2017 1st International Conference on Next Generation Computing Applications (NextComp). Mauritius: IEEE.

MOFLI. (2011). Master plan 2011-2021. Ulaanbaatar, Mongolia. Retrieved from www.mofa.gov.mn: http://mofa.gov.mn/exp/ ckfinder/userfiles/files/master2011-2021.pdf

MOFALI. (2018). Vegetable production. Retrieved from Ministry of Food, Agriculture and Light Industry: http://mofa.gov.mn/exp/ blog/8/71\#

MOFALI. (2019). tentsel20179.pdf. Retrieved from http://mofa.gov. $\mathrm{mn} /$ : http://mofa.gov.mn/exp/ckfinder/userfiles/files/tentsel20179.pdf

Murata, K., ITO, A., Takahashi, Y. and Hatano, H. (2018). A Study on Growth Stage Classification of Paddy Rice by CNN using NDVI Images. Proceedings of ICCSCS2018

NSO. (2018). Report of Mongolian Agriculture 2018. Ulaanbaatar: National Statistical Office of Mongolia.

NSO. (2019). National Statistics Office of Mongolia. Retrieved from www.1212.mn: https://www.1212.mn/ tables.aspx?tbl id=DT NSO 1001 038V3\&BAG select

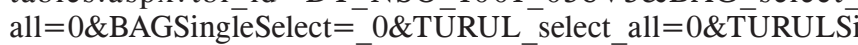
ngleSelect $=\_112 \&$ YearY_select_all $=1 \&$ YearYSingleSelect $=\&$ vie wtype $=$ linechart
Parrot SEQUOIA. (n.d.). Retrieved December 28, 2018, from

https://www.parrot.com/business-solutions-us/parrot-professional/ parrot-sequoia\#parrot-sequoia-

Veroustraete, F. (2015). The Rise of the Drones in Agriculture. Ecronicon (pp. 325-327). Belgium: Agriculture editorial. 